\title{
CONCEPÇÕES DE GESTORES E MONITORES SOBRE O ESPORTE NO PROGRAMA MAIS EDUCAÇÃO: POR UMA PEDAGOGIZAÇÃO DA PRÁTICA ESPORTIVA
}

D.T.S. Rizzo ${ }^{1,2 *}$; A.C.M.Aranha ${ }^{2}$; C.M.S.M.Freitas ${ }^{3}$; A.P.M.Sousa ${ }^{4}$; J.M.Ramires ${ }^{5}$ e J.C.Lopes ${ }^{2,6}$ 1 Faculdade de Educação Física - Faculdades Magsul (FAMAG), 79900-000, Ponta Porã - MS, Brasil 2 Universidade de Trás os Montes e Alto Douro (UTAD) 5000-558, Vila Real, Portugal 3 Universidade de Pernambuco (UPE) / Universidade Federal da Paraíba (UFPB), 50100-130, Recife, PE, Brasil 4 Faculdade de Educação Física - Faculdades Magsul (FAMAG), 79900-000, Ponta Porã - MS, Brasil 5 Faculdade de Educação Física - Faculdades Magsul (FAMAG), 79900-000, Ponta Porã - MS, Brasil 6 Universidade de Ribeirão Preto - UNAERP, 14096-380 Ribeirão Preto - SP, Brasil

$$
\text { deyvidrizzo1@gmail.com }
$$

\section{RESUMO}

As políticas públicas para o desenvolvimento e sistematização do esporte vêm sendo um destaque no cenário nacional. Este trabalho tem como objetivo investigar qual a concepção e perspectivas laborais dos gestores e monitores do Programa Mais Educação (PME) de uma escola municipal situada no estado de Mato Grosso do Sul em relação ao esporte, acompanhando algumas aulas do macro campo esporte e lazer e observando quais as atividades vêm sendo oferecidas aos alunos. Para isso, utilizou-se na metodologia uma abordagem qualitativa, estruturada a partir de uma pesquisa bibliográfica e de campo, subsidiando-se em observações de aulas e aplicação de questionário e entrevista para sujeitos que compõem a monitoria e gestão do PME. Foi possível através dos dados coletados concluir que as aulas são pautadas apenas em conteúdos lúdicos e brincadeira, faltam elementos concretos para a realização de qualquer prática esportiva.

\section{CONCEPTIONS MANAGERS AND MONITORS ON SPORT NO MORE EDUCATION PROGRAM: FOR A PEDAGOGIZATION OF SPORT PRACTICE}

\begin{abstract}
Public policies for the development and systematization of the sport have been a highlight on the national scene. This study aims to investigate the design and job prospects of managers and monitors the More Education Program (MEP) of a municipal school in the state of Mato Grosso do Sul in relation to the sport, following some classes of macro sports field and recreation and observing which activities are being offered to students. For this, we used a qualitative approach in the
\end{abstract}

methodology, structured from a literature search and field, assisting in class observations and application of questionnaire and interview subjects that make up the monitoring and management of MEP. It was made possible through the collected data to conclude that the classes are guided only in entertainment contents and games, lacking concrete elements for the realization of any sport.

KEYWORDS: pedagogy, sports, education. 


\section{INTRODUÇÃO}

O presente estudo objetiva analisar as concepções e as perspectivas laborais que os gestores e monitores do PME têm sobre o esporte. Deste modo inicialmente foi feito um levantamento teórico procurando obter todas as informações necessárias sobre o PME, algumas considerações sobre o esporte, como é o contato que os alunos têm com essa prática de acordo com o ensinamento de seus professores. Assim como estudar o funcionamento do PME como uma Política Pública educacional, um programa governamental e o seu funcionamento; foram estes os passos iniciais para o início do estudo.

O esporte com tratamento educacional se mostra de extrema relevância para a sociedade, sobretudo quando pensamos nas novas gerações, responsáveis, em primeira instância, pelas mudanças sociais futuras e pela renovação dos valores e tradições. Se as tradições estão em constante reconstrução, valores novos surgem, nem sempre tão positivos ou altruístas como eticamente desejável. Impõe-se então a responsabilidade moral da sociedade em geral, com ênfase na família, escola e demais instituições encarregadas de educar formalmente os jovens, pelo processo de transmissão de valores positivos (RIZZO, et al. 2014)

O reconhecimento do esporte como canal de socialização positiva ou inclusão social é revelado pelo crescente número de projetos esportivos destinados aos jovens das classes populares, financiados por instituições governamentais e privadas. São exemplares os programas alternativos paralelos à educação formal, de iniciação profissional e educação através do esporte e do trabalho, que surgiram a partir da década de 80 (VIANNA; LOVISOLO, 2011).

Desenvolver práticas que abarquem o esporte nas aulas de Educação Física exige do professor conhecimento e atenção com os alunos, assim como encontrar soluções para situações adversas como a falta de espaço físico e material. Mas o professor deve estar preparado par lidar com essas situações, não se acomodar, preparado para ministrar suas aulas de maneira com que o aluno sinta alegria em participar e gostar do que está fazendo, não sendo obrigado, mas sim praticar de livre e espontânea vontade.

É nesse âmbito que o tratamento educacional no esporte, pautado em valores positivos pode se mostrar eficaz, pois é através desse processo que os jovens terão a oportunidade de se relacionar com as mais diferenciadas modalidades desportivas, podendo até mesmo se identificar com alguma, e com os cuidados necessários se tornar um atleta de alto nível (RIZZO et al., 2014).

O estudo se mostra relevante, pois são vários os resultados positivos que as práticas esportivas podem trazer aos jovens e às crianças, tais como: o aumento da autoestima, motivação, melhoria dos resultados estudantis, possibilidades de afastamento do tabagismo, álcool e drogas. Interessante ressaltar que crianças participam destas atividades por motivações intrínsecas (prazer, divertimento) e não por escolha ou pressão dos pais. (MAHONEY, HARRIS e ECCLES, 2006).

Bracht (1986), Kunz (2000) Gaya, (2000) Taffarel, (2000) Stigger (2001) e Vaz (2001) demonstraram por meio de suas pesquisas que o estudo acerca do esporte de rendimento no ambiente escolar é abstruso e seus resultados não possuem questões comuns. $O$ que leva a conclusão de que esta temática possui variações significativas e merece confrontos e debates intelectuais.

Ainda é preciso algumas mudanças para significação da prática docente de alguns profissionais de Educação Física, que talvez possam ser sanadas com cursos de formação continuada. Com essa pesquisa pode-se perceber que as aulas são voltadas mais para o lúdico, envolvendo brincadeiras e jogos competitivos e cooperativos, onde o esporte é pouco mencionado assim como seus objetivos. 
Os diferentes elementos constitutivos das modalidades esportivas - fundamentos, princípios, características, regras, estratégia e tática do jogo, entre outros, devem ser, aos poucos, apresentados de maneira simples e em nível de exigência adequado às habilidades e capacidades físicas, motoras, cognitivas, emocionais e sociais de uma criança que está iniciando um novo processo (MACHADO et al. 2015).

Daí o interesse de fazer uma interface entre educação e esporte, pois nos dias atuais, no âmbito das ciências do desporto, carecemos de uma reconstrução do esporte, ou seja, uma prática que lide com o coletivo ao invés de apenas individualidades, que seja plural à singular, que de homogêneo passe a ser heterogêneo, enfim, percebe-se que são caracterizações que podem ser conquistadas por meio do desenvolvimento de um projeto comprometido com sistematização da prática esportiva como meio de socialização.

$\mathrm{O}$ esporte aparece como a atividade alternativa dominante à rua. $\mathrm{O}$ suposto é que as crianças e jovens gostam do esporte e que, portanto, participarão dos projetos. A crítica a utilização dos esportes como instrumento de inclusão encontra-se disseminada em setores do meio acadêmico, em particular nos cursos de formação em educação física, com a difusão da ideia de que o esporte é um mal em si, sendo impossível a sua utilização para a autonomia e emancipação dos membros das camadas populares. Mais ainda, o esporte por "essência" seria excludente por selecionar os melhores (VIANNA; LOVISOLO, 2011).

Contanto, encontramos estudos contrários a essa idéia, e ainda possibilitam entender que o esporte contribui para a melhoria d qualidade de vida das pessoas (GAYA, 2009; STIGGER, 2009; VAZ, 2009).

A partir desses pressupostos, o estudo se norteia com a seguinte pergunta: Quais as significações que coordenação e as monitoria do PME possuem em relação ao macro campo do esporte? Partindo do entendimento que a reflexão no contexto da prática esportiva deve ter como horizonte de princípios oportunizar discussões que fomentem o senso crítico de seus alunos, para que os mesmos não sejam influenciados por elementos impostos pelo senso comum (RIZZO e SOUZA, 2013).

Esta é, sem dúvida, uma questão que merece muita atenção, pois, se a prática esportiva não for baseada em princípios que se configurem em oportunidades no sentido da prática corporal, cooperação e valorização às diferenças, estaremos criando obstáculos para a inclusão social dos participantes (BELTRAME; SAMPAIO, 2015)

Com esse estudo, considerou-se que a gestão e monitoria do PME apresentaram-se interessados na disseminação de uma prática esportiva que desenvolva o gosto pelo esporte nos alunos e deixaram claras as expectativas que por meio da atividade física os alunos consigam melhorar o desempenho em outras unidades curriculares em sala de aula. Contudo, apontou-se a necessidade de melhor preparação desses profissionais principalmente para seleção, organização e aplicação de conteúdos, pois se o programa pretende utilizar a prática esportiva para significar o movimento historicamente produzido pelo ser humano, essa ação deve estar pautada numa pedagogia do esporte que ofereça sentido e significado as atividades físicas.

\section{METODOLOGIA}

Para alcançar os objetivos do trabalho, utilizou uma pesquisa de natureza qualitativa, explicitando os instrumentos e procedimentos utilizados para a coleta de dados e assim poder obter os resultados desejados. Outros procedimentos foram adotados, como a pesquisa bibliográfica e a de campo. 
Inicialmente foi feito um contato com a escola denominada de Escola $A B$, onde foi apresentada a pesquisa para direção, coordenação e as monitoras do macro campo do esporte, denominadas de Monitora A e Monitora B. Assim após a explicação de todo o trabalho e aceitação do mesmo, foi entregue o Termo de Autorização Institucional e o Termo de Autorização de Consentimento Livre e Esclarecido, a coordenadora do PME e também foi entregue as Monitoras A e B.

"A pesquisa qualitativa costuma ser direcionada, ao longo de seu desenvolvimento, seu foco de interesse é amplo. Dela faz parte a obtenção de dados descritivos e interativo do pesquisador com a situação objeto de estudo" (NEVES, 1996, p. 01).

Em certa medida, "os trabalhos qualitativos se assemelham a procedimentos de interpretação dos fenômenos que empregamos no nosso dia-a-dia, que têm a mesma natureza dos dados que o pesquisador qualitativo emprega em sua pesquisa" (NEVES, p. 10). Compreende-se que a pesquisa qualitativa possui um caráter exploratório, em que seus objetivos são: a observação, a descrição, a compreensão e o significado.

$\mathrm{Na}$ pesquisa bibliográfica foi feito um levantamento dos teóricos que investigaram sobre a temática escolhida. Dentre alguns que apontamos como de extrema relevância, tais como: TUBINO (2010); BRACHT et al. (2003); BRASIL (2013).

Na pesquisa de campo, foi feita a coleta de dados através da adoção de alguns instrumentos de pesquisa, como: a observação de quinze aulas do macro campo esporte do PME, em que as Monitoras A e B, ministraram aulas, sete aulas da Monitora B, no período matutino e oito aulas da Monitora A, no período vespertino e aplicação da entrevista semiestruturada com oito perguntas para cada uma delas.

Essas entrevistas foram realizadas num dia que as monitoras estavam em hora atividade na escola, destarte, primeiramente a Monitora A foi entrevistada, e logo após a Monitora B.

Monitora A: 21 anos de idade, está concluindo o Ensino Superior na área de Educação Física, com experiência, pois já ministrou aulas de Educação Física em uma Escola Estadual de Ponta Porã - MS. A mesma já foi atleta de handebol e atletismo, e para exercer a função de monitora do macro campo esporte e lazer foi indicada pela coordenação da escola onde inicialmente levou o seu currículo.

Monitora B: 20 anos de idade, está cursando o Ensino Superior na área de Pedagogia, primeira experiência em contato com os alunos. A mesma foi indicada pela coordenação da escola após enviar o seu currículo.

Também foi aplicado um questionário para coordenadora do PME numa sala fechada sem a interferência de outras pessoas. O roteiro do questionário foi elaborado previamente, contendo sete questões para as monitoras e um questionário com nove perguntas para a coordenadora. Segundo Lakatos e Marconi (1988), o questionário é um instrumento que se constitui como uma série de perguntas ordenadas, que devem ser respondidas por escrito, não sendo necessária a presença do entrevistador.

As perguntas selecionadas referem-se aos objetivos traçados, desde como é o funcionamento do PME na escola até a relação, aceitação e prática do esporte feita pelos alunos. A análise de dados foi feita considerando as respostas feitas pelo questionário, as entrevistas realizadas assim como a bibliografia utilizada.

Segundo Lakatos e Marconi (1988) após a verificação dos dados e obtidos os resultados, a etapa seguinte e a análise e interpretação dos mesmos. Para a análise considerou-se as respostas sobre o olhar da coordenadora e o conhecimento sobre o campo Esporte e comparados com o 
Manual do PME e também as respostas das monitoras com relação a prática pedagógica e ensinamento do esporte aos alunos, os conteúdos ministrados, o conhecimento das mesmas e as mudanças obtidas.

O local de pesquisa foi uma escola da rede municipal de ensino localizada no estado de Mato Grosso do Sul; denominada de Escola AB. Deste modo, as aulas foram acompanhadas por meio da observação não participante, em que todas as percepções e entendimento do pesquisador foram anotadas em um diário de campo.

As aulas observadas referem-se aos trabalhos desenvolvidos na área da Educação Física, especificamente no campo esportivo, em que foram considerados alguns critérios para observar de forma mais detido, como por exemplo: como os esportes são praticados; o trabalho das monitoras; o interesse e motivação dos alunos ao realizarem as atividades propostas.

$\mathrm{Na}$ observação não-participante, o pesquisador toma contato com os sujeitos da pesquisa, mas sem integrar-se a eles; permanece de fora. Presencia o fato, mas não participa dele; não se deixa envolver pelas situações; faz mais o papel de espectador. Isso, porém, não quer dizer que a observação não seja consciente de sua prática, dirigida, ordenada para um fim determinado (LAKATOS; MARCONI, 1998).

Assim, objetivando alcançar respostas e as inquietudes levantadas, essas aulas foram observadas durante duas semanas, sendo uma semana no período matutino com a professora $\mathrm{B}$ e uma semana no período vespertino com a professora A.

A Escola Municipal, situada no Estado de Mato Grosso do Sul foi criada no ano de 2006 pela antiga administração da Prefeitura Municipal. São mais de trezentos alunos escritos no PME. É uma escola construída em alvenaria contendo dez salas de aula, sala de STE (Sala de Tecnologia Educacional), sala para os professores que funciona em conjunto com a Coordenação Pedagógica, ficando disponível oito sala de aulas, sala de direção, sala para secretaria, sala multidisciplinar, sala de leitura, despensa, cozinha, dois banheiros para professores e funcionários, oito banheiros para os alunos e dois para alunos usuários de cadeiras de rodas. Também possui um parque infantil, um campinho de futebol e uma quadra coberta, construída recentemente.

O PME funciona em uma extensão situada em frente à escola, onde funcionava a Associação de moradores do bairro. Os alunos do PME realizam as atividades nessa extensão, onde trata-se de um salão que possui divisórias internas improvisadas para as aulas, sendo separadas cinco salas, uma delas onde se guarda os materiais pedagógicos, e dois banheiros.

Foram cumpridos os princípios éticos para realização do presente estudo, visando minimizar a possibilidade de exploração e assegurando o respeito aos participantes da pesquisa enquanto contribuintes para o bem social e científico. Conforme Lakatos e Marconi (1988, p. 90), na observação "utiliza-se os sentidos na obtenção de determinados aspectos da realidade. Consiste de ver, ouvir e examinar fatos ou fenômenos".

\section{RESULTADOS E DISCUSSÃO}

Nesta parte do estudo é discutida a relação das respostas obtidas no questionário e o roteiro de entrevista comparando-os com os objetivos da pesquisa e também relacionando-as com o Manual do Programa Mais Educação - PME. De acordo com o questionário respondido, quem coordena o PME na escola investigada é uma professora de 48 anos que cursou o antigo magistério (4 anos). Possuí Graduação Normal Superior na Universidade Estadual de Mato Grosso do Sul (UEMS) e Especialização em Educação Infantil e Séries Iniciais. 
O PME funciona na Escola AB desde o ano de 2011. No período matutino no horário das $08 \mathrm{~h} 00 \mathrm{~min}$ as $12 \mathrm{~h} 00 \mathrm{~min}$ e vespertino das $12 \mathrm{~h} 00 \mathrm{~min}$ as $16 \mathrm{~h} 00 \mathrm{~min}$. Ao total são 10 monitores que estão no PME, sendo 05 no período matutino e 05 no vespertino. Destas duas são monitoras do macro campo Esporte e Lazer, sendo uma para cada turno: matutino e vespertino.

Os conteúdos ministrados para as turmas são planejados num dia da semana onde realizam a hora atividade, essa é feita em um único horário onde todas as monitoras juntamente com a coordenadora realizam essas atividades juntas. Assim as monitoras do macro campo Esporte e Lazer preparam as aulas juntas, uma troca experiência com a outra, dão sugestões e fazem juntas, o plano didático.

Para as monitoras ministrarem as aulas não é ofertado nenhum tipo de treinamento, pois não é exigida a formação em nível superior. Então nesse caso como ensinar os alunos o real objetivo das práticas esportivas com alguém que também não tenha esse conhecimento? Para isso seria importante um treinamento onde pudesse ser ofertado conhecimento as monitoras que exercerão essa função, um treinamento adequado seria bom para que assim pudessem ensinar os valores das práticas esportivas.

Para iniciar as atividades as monitoras recebem orientação da coordenação na elaboração das atividades propostas. Para ser um monitor é necessário que o mesmo tenha completado 16 anos de idade, que seja uma pessoa de boa índole na comunidade, participativa no grupo social, com atitudes que demonstrem ser comprometida e responsável.

O trabalho de monitoria deverá ser desempenhado, preferencialmente, por estudantes universitários de formação específica nas áreas de desenvolvimento das atividades ou pessoas da comunidade com habilidades apropriadas, como, por exemplo, instrutor de judô, mestre de capoeira, contador de histórias, agricultor para horta escolar, etc. Recomenda-se a não utilização de professores da própria escola para atuarem como monitores, quando isso significar ressarcimento de despesas de transporte e alimentação com recursos do Fundo Nacional de Desenvolvimento da Educação (BRASIL, p.23).

Os esportes trabalhados nessa instituição no macro campo esporte e lazer são basquete, vôlei, handebol, futebol e atletismo, busca-se fazer com que o aluno através do lúdico vivencie diversas modalidades. Segundo a Coordenadora do PME da Escola AB, a escolha desses esportes tem como objetivo, o desenvolvimento do estudante em todos os aspectos, como físico, motor, intelectual, social e no convívio em grupo, respeitando o espaço do outro.

Assim a escolha desses macros campos é feita em conjunto com a direção, coordenação, professores tanto do PME quanto da própria Escola AB. A Coordenadora ainda diz que com essas atividades, ocorreram mudanças visíveis, tanto em relação a aprendizagem em sala de aula, elevação do índice do IDEB da escola e a disciplina em sala de aula.

Para a avaliação dos alunos existe um encontro semanal entre coordenação e monitores para trocar experiências, relatos e planejamento das aulas. Por meio de um conselho de classe são relatadas as dificuldades e aprendizagens de cada estudante, buscando soluções para superar as defasagens.

O PME é oferecido a todos os alunos do $1^{\circ}$ ao $3^{\circ}$ ano do ensino fundamental, sem distinção. Assim, segundo a coordenadora, depois que o PME foi implantado houve grandes melhoras com relação à educação, um dos pontos positivos é a elevação do índice do IDEB na escola e um dos pontos negativos é ainda a falta de estrutura, espaço inadequado para a realização das atividades.

Ensinar o esporte exige do professor de Educação Física conhecimento e dedicação. O que acontece nas aulas ministradas em sua maioria são atividades direcionadas apenas para lúdico, 
principalmente com os alunos do $1^{\circ}$ ano do ensino fundamental, onde em sua maioria são aulas com diversas brincadeiras. Pode-se perceber que o esporte em si é pouco apresentado aos alunos da $3^{\circ}$ série, onde rapidamente são mencionadas algumas modalidades.

Assim, o aluno não consegue aprender se não for apresentado ao esporte, suas modalidades, práticas. Cabe ao professor de Educação Física iniciar desde as séries iniciais, instigando ao aluno conhecer as abrangências da manifestação esportiva. $O$ momento da preparação da aula em conjunto entre as monitoras favorece a Monitora B, que parece não possuir os conhecimentos necessários para significação do esporte na vida dos alunos. Pois em diversos momentos da entrevista aparece insegura de sua prática enquanto profissional.

O aluno possui curiosidade em aprender algo novo e um profissional que não esteja apto a ensinar, pode trazer danos futuramente a esse aluno. Nas aulas observadas não são focadas nenhuma modalidade esportiva em especial, e as que são mencionadas ao aluno, são as mais populares consideradas hegemônicas, a saber: o voleibol, futsal e basquetebol.

Com relação ao conhecimento sobre o esporte a Monitora A apresenta um conhecimento maior, talvez por estar cursando o Ensino Superior no curso de Educação Física, tem facilidade em responder as questões sobre o esporte, destaca com plenitude a importância da socialização, cooperação e inclusão social dos alunos por meio do esporte, realiza aulas expositivas e práticas; os conteúdos são apresentados aos alunos e vivenciados respeitando o repertorio motor de todos.

A Monitora B, possui poucos conhecimentos sobre o esporte; cursa o Ensino Superior em Pedagogia e diz que prepara as aulas junto com a Monitora A, assim sempre tira dúvidas e pede ajuda na elaboração das mesmas, sempre para não fugir do objetivo que é trabalhar a socialização, cooperação e desenvolvimento do aluno.

O discurso ideológico presente em programas e políticas de inserção social através do esporte, que postula apenas uma perspectiva de inclusão pelo lazer, parece não suscitar a adesão e permanência de parcelas significativas dos matriculados nas atividades. Deve ficar claro que a realização de atividades esportivas orientadas à profissionalização, mediante treinos suficientes e participação em eventos esportivos, não significa automaticamente permanência ou adesão. De fato, a partir de certo momento, os praticantes podem chegar à conclusão de que lhes falta talento, algum dom natural, de que não são suficientemente bons e abandonam a atividade.

O esporte é um universo amplo, uma totalidade com várias formas de manifestações, e por isso seu entendimento não pode ser reduzido a uma única forma de expressão, é preciso considerar seus diferentes contextos (STIGGER, 2002).

Desse modo, ao mapear esse tipo de desenvolvimento dos de crianças que pratica esportes temos a possibilidade de desenvolver estratégias de promoção de saúde pautadas na promoção de valores positivos, com vistas a diminuir a vulnerabilidade na juventude a comportamentos de risco, sendo que, alguns desses comportamentos de risco podem ter efeitos negativos e agir diretamente não somente na vida de um jovem, mas refletir em todo um grupo social. Por isso, a importância de estudar o esporte como elemento integrador da vida dos sujeitos, e demonstrar que os programas centrados no esporte com tratamento educacional são fundamentais para a vida ativa e positiva de um jovem (RIZZO et al. 2014).

Falar sobre o que é o esporte em um único conceito é difícil, pois existem várias expressões para sua definição, é muito mais do que apenas uma prática homogênea e singular, é amplo pela sua totalidade de movimentos e grávido de significados.

De acordo com a coordenação e as monitoras assim como os professores, os mesmos realizam reuniões para discutir os avanços obtidos, e os resultados indicam que os alunos possuem 
uma melhora no comportamento após as o envolvimento com as práticas físicas, além de se expressarem melhor em público e desenvolverem atividades em grupo.

Os alunos também demonstram muito gosto pelas práticas, realizam pedidos para conhecer algumas modalidades e também fazem pesquisas sobre o que é abordado nas aulas. Contudo, as aulas observadas caracterizam-se em sua maioria como práticas de atividades lúdicas que envolvem brincadeiras diversas.

\section{CONCLUSÃO}

A maneira de tratar conteúdos que envolvam práticas de esporte aos alunos não vem pronta como uma receita no qual se deve seguir, esse ensino é transmitido de diversas maneiras e depende da prática pedagógica de cada profissional.

Pode-se considerar que é importante ter um programa que de atenção especial ao esporte para os alunos, assim como o PME, que pode funcionar com o olhar voltado para a realidade social do aluno, que pense e trabalhe para o seu desenvolvimento. Por meio do esporte, verificou-se que a escola trabalha em conjunto com a coordenação do programa para obter resultados positivos e alcançar os objetivos, alguns ainda são falhos como a seleção de monitores despreparados.

Trabalhar o esporte dentro de qualquer instituição ainda é visto como processo de seleção de atletas profissionais, mas cabe ao professor desenvolver conteúdos que proporcionem momentos de uma prática esportiva heterogênea, ou seja, que possibilite a participação de todos.

Os gestores e monitores apresentaram-se interessados na disseminação de uma prática esportiva que desenvolva o gosto pelo esporte nos alunos e deixaram claras as expectativas que por meio da atividade física os alunos consigam melhorar o desempenho em outras unidades curriculares em sala de aula.

Contudo, apontou-se a necessidade de melhor preparação desses profissionais principalmente para seleção, organização e aplicação de conteúdos, pois se o programa pretende utilizar a prática esportiva para significar o movimento historicamente produzido pelo ser humano, essa ação deve estar pautada numa pedagogia do esporte que ofereça sentido e significado as atividades físicas.

Notou-se que as aulas são lúdicas e envolvem jogos e brincadeiras cooperativas, onde grande parte das aulas é baseada somente em brincadeiras. A crítica não é a utilização do lúdico no ambiente de Jogos no PME, mas sim a falta de ênfase no esporte propriamente dito. O esporte pautado no tratamento educional também envolve o lúdico, contudo não se pode esquecer da "essência" do esporte, ou seja, se alunos vão fazer um jogo lúdico com a bola e o chute, isso de alguma forma deve mostrar alguma ligação com o futebol. Mas essa significação deve ser realizada pelos alunos e instigada pelo professor, que neste caso são os monitores.

A prática do esporte pode ser para todos e supõe-se que qualquer pessoa pode praticar atividades esportivas se o tratamento pedagógico estiver pautado na prática docente; sem distinções de gênero ou idade, onde todos possam se sentir vontade em vivenciar o esporte. Contudo, para desenvolver uma prática que englobe o esporte nas aulas é necessário ter conhecimento dos sentidos, significados e dimensões da prática esportiva na sociedade.

O benefício da presença do esporte na vida de crianças é uma problemática que acompanha a história de pesquisadores dessa área do conhecimento, pesquisas indicam que o esporte contribui para melhorar as relações interpessoais, distancia da violência, das drogas, melhora a saúde física e mental, favorece para desenvolvimento da qualidade de vida, enfim, seja no âmbito cultural, 
biológico ou social a lista dos benefícios é extensa. Contanto, para que cada uma dessa premissas ocorra, o resultado é dependente do envolvimento e compromisso profissional.

\section{AGRADECIMENTOS E APOIO FINANCEIRO}

Faculdade de Educação Física - Faculdades Magsul (FAMAG)

\section{REFERENCIAS}

BELTRAME, A. L. N.; SAMPAIO, T. M. V. Service specializing in sport adapted: discussing the sports initiation from the perspective of inclusion. Revista da Educação Física / UEM, v. 26, n. 3, p. 377-388, set. 2015.

BRACHT, V. A criança que pratica esporte respeita as regras do jogo... capitalista. Revista Brasileira de Ciências do Esporte, São Paulo, v. 7, n. 2, jan.1986.

BRACHT, V. et al. Pesquisa em ação: Educação Física na escola. Ijuí, RS: Unijuí, 2003.

BRASIL. Ministério da Educação. Manual operacional de educação integral. Brasília: SEB, 2013.

GAYA, A. Sobre o Esporte para Crianças e Jovens. Movimento, Porto Alegre, n. ${ }^{\circ}$ 13, 2000.

GAYA, A. Sobre o esporte para crianças e jovens. In: STIGGER, M. P.; LOVISOLO, H. R. (Eds.). . Esporte de rendimento e esporte na escola. Campinas: Autores Associados, 2009.

KUNZ, E. Esporte: uma abordagem com a fenomenologia. Movimento, Porto Alegre, n. 12, p. I-XIII, jul. 2000.

LAKATOS, Eva Maria; MARCONI, Marina de Andrade. Fundamentos de metodologia científica. São Paulo: Atlas, 1988.

MACHADO, G. V; GALATTI, L. R; PAES, R.P. Pedagogia do Esporte e Projetos Sociais: Interlocuções sobre a prática esportiva. Rev. Movimento, Porto Alegre, v. 21, n. 2. p. 405-418, abr./jun. de 2015.

NEVES, José Luis. Pesquisa qualitativa: características, usos e possibilidades. Caderno de Pesquisas em Administração. São Paulo, v.1, n. 3, 2º sem./1996. Disponível em: <http://www.ead.fea.usp.br/cad-pesq/arquivos/C03art06.pdf> Acesso em: 17 dez. 2015.

MAHONEY, H. A.; ECCLES, J. Organized Activity Participation, Positive Youth Development, and the OverScheduling Hypothesis. Social Policy Report, 20, 4, 3 -30, 2006.

RIZZO, D.T.S; FERREIRA, A.M.L.; SOUZA, W.C. Desenvolvimento Positivo dos Jovens (DPJ) através do Esporte: perspectivas em países da língua portuguesa. Conexões: revista da Faculdade de Educação Física da UNICAMP, Campinas, v. 12, n. 3, p. 106-120, jul./set. 2014.

RIZZO, D. T. S. SOUZA, W. C. S. Educação Física Escolar na sociedade contemporânea: Desafios e Perspectivas. Educação Física em Revista - EFR, v. 7, n. 3, p. 56-63. 2013.

STIGGER, M. P. Relações entre o esporte de rendimento e o esporte da escola. Movimento, Porto alegre, v.7, n.14, 2001.

STIGGER, M. P. Esporte, lazer e estilos de vida: um estudo etnográfico. Campinas: Autores Associados, 2002.

TAFFAREL, C. N. T. Desporto Educacional: realidade e possibilidades das políticas governamentais e das práticas pedagógicas nas escolas públicas. Movimento, Ano VII. No 13, 2000.

VAZ, A. F. Técnica, Esporte, Rendimento. Movimento, Porto Alegre, v. 7, p. 87-99, 2001.

TUBINO, Manoel J. G., Estudos brasileiros sobre o esporte: ênfase no esporte-educação. Maringá: Autores Associados, 2010.

VAZ, A. F. Técnica, esporte, rendimento. In: STIGGER, M. P.; LOVISOLO, H. R. (Eds.). . Esporte de rendimento e esporte na escola. Campinas: Autores Associados, 2009.

VIANNA, J. A.; LOVISOLO, H. R. The social inclusion through the sport: the perception of the teachers. Revista Brasileira de Educação Física e Esporte, v. 25, n. 2, p. 285-296, jun. 2011. 